\title{
Double-stapled transanal rectotomy (STARR procedure) for obstructed defecation syndrome seems to have a low degree of acceptance amongst older surgeons
}

\author{
Peter Ambe • L. Köhler • B. Janghorban-Esfahani • \\ A. Meyer
}

Accepted: 24 November 2009 / Published online: 15 December 2009

(C) Springer-Verlag 2009

\section{Dear Editor:}

We have been studying the evolution of double-stapled transanal rectotomy (STARR) with great care and interest and came to the conclusion that, despite an increasing number of studies and publications showing the efficacy of the procedure [1], there still seems to be a low degree of acceptance amongst older surgeons.

Mario Pescatio et al. published a paper on two cases of rectovaginal fistula following the STARR procedure [2]. Rectovaginal fistulas definitely belong to the possible complications associated with the procedure [2]. However, there is no surgical procedure void of complications. The incidence and severity of surgical complications depend on many factors, the most important of which is the surgeon!

Most important, however, are the clinical and subjective results following the STARR procedure. A great degree of clinical and subjective relief has been described in many publications [3]. The STARR procedure is accompanied by less postoperative pain, a shorter hospital stay and a faster return to work, just to name a few. These are factors that greatly influence the patients' socio-economic life.

Nowadays, patients present with printouts from extensive internet research demanding new and less invasive surgical procedures. The surgical decision no longer lies in the hands of the surgery alone! The patient's choice is legally binding and greatly influences the choice of surgical procedures.

We do agree that obstructed defecation has a multifactor aetiology, and there is need of an extensive diagnostic work

up (dynamic perineal ultrasound studies, defecography, MRI, etc.), as well as non-surgical therapeutic measures (biofeedback, laxatives, etc.) prior to surgery.

At the moment however, we consider the procedure based on numerous publications and our institutional experience as safe and adequate in the treatment of patients with surgically treatable causes of obstructed defecations syndrome [4].

Serious complications including rectovaginal fistula remain rare with adequate surgical training. The question is "is this low degree of acceptance of the STARR procedure amongst older surgeons related to unwillingness to learn new surgical techniques?"

\section{References}

1. Boccasanta P, Venturi M, Samamina G, Cesana BM, Bemasconi F, Roviaro G (2004) New trends in the surgical treatment of outlet obstruction; clinical and functional results of two novel transanal stapled techniques from a randomized controlled trial. Int $\mathrm{J}$ Colorectal Dis 19:359-369

2. Pescatori M, Dodi G, Salafia C et al (2005) Rectovaginal fistula after double stapled transanal rectotomy (STARR) for obstructed defecation. Int J Colrectal Dis 20:83-85

3. Paolo B, Marco V, Giovanni S et al (2004) New trends in the surgical treatment of outlet obstruction: clinical and functional results of two novel transanal stapled techniques from a randomized controlled trial. Int J Colrectal Dis 19:359-369

4. Bouchoucha M, Devroede G, Arsac M (2004) Anismus: a marker of multi-site functional disorder? Int J Colorectal Dis 19:374-379

P. Ambe $(\triangle) \cdot$ L. Köhler $\cdot$ B. Janghorban-Esfahani $\cdot$ A. Meyer Surgical Department, St. Elizabeth Krankenhaus,

Kreiskrankenhaus,

Von-Werth-Str. 5,

41515 Grevenbroich, Germany

e-mail: peter.ambe@kkh-ne.de 